\title{
Deciphering Multiple Sclerosis Progression
}

\author{
Virginia Meca-Lallana ${ }^{1}$, Leticia Berenguer-Ruiz ${ }^{2}$, Joan Carreres-Polo ${ }^{3}$, \\ Sara Eichau-Madueño ${ }^{4}$, Jaime Ferrer-Lozano ${ }^{5}$, Lucía Forero ${ }^{6}$, Yolanda Higueras ${ }^{7,8}$, \\ Nieves Téllez Lara ${ }^{9}$, Angela Vidal-Jordana ${ }^{10}$ and Francisco Carlos Pérez-Miralles ${ }^{11,12 *}$
}

${ }^{1}$ Multiple Sclerosis Unit, Neurology Department, Fundación de Investigación Biomédica, Hospital Universitario de la Princesa, Madrid, Spain, ${ }^{2}$ Neurology Department, Hospital Marina Baixa, Alicante, Spain, ${ }^{3}$ Neuroradiology Section, Radiology Department, Hospital Universitari i Politècnic La Fe, Valencia, Spain, ${ }^{4}$ Multiple Sclerosis CSUR Unit, Neurology Department, Hospital Universitario Virgen Macarena, Seville, Spain, ${ }^{5}$ Department of Pathology, Hospital Universitari i Politècnic La Fe, Valencia, Spain, ${ }^{6}$ Neurology Department, Hospital Puerta del Mar, Cádiz, Spain, ${ }^{7}$ Neurology Department, Instituto de Investigación Sanitaria Gregorio Marañón (IISGM), Hospital Universitario Gregorio Marañón, Madrid, Spain, ${ }^{8}$ Department of Experimental Psychology, Cognitive Processes and Speech Therapy, Universidad Complutense, Madrid, Spain, ${ }^{9}$ Neurology Department, Hospital Clínico Universitario de Valladolid, Valladolid, Spain, ${ }^{10}$ Neurology/Neuroimmunology Department, Centre d'Esclerosi Múltiple de Catalunya (Cemcat), Hospital Universitari Vall d'Hebron, Barcelona, Spain,

${ }^{11}$ Neuroimmunology Unit, Neurology Department, Hospital Universitari i Politècnic La Fe, Valencia, Spain, ${ }^{12}$ Department of Medicine, University of València, Valencia, Spain

\section{OPEN ACCESS}

Edited by:

Valentina Tomassini,

University of Studies G. d'Annunzio

Chieti and Pescara, Italy

Reviewed by:

Luca Prosperini,

San Camillo-Forlanini Hospital, Italy Carlo Pozzilli,

Sapienza University of Rome, Italy

${ }^{*}$ Correspondence:

Francisco Carlos Pérez-Miralles fcomiralles@comv.es

Specialty section

This article was submitted to Multiple Sclerosis and Neuroimmunology, a section of the journal Frontiers in Neurology

Received: 20 September 2020 Accepted: 11 March 2021 Published: 07 April 2021

Citation:

Meca-Lallana V, Berenguer-Ruiz L, Carreres-Polo J, Eichau-Madueño S, Ferrer-Lozano J, Forero L, Higueras Y,

Téllez Lara N, Vidal-Jordana A and Pérez-Miralles FC (2021) Deciphering Multiple Sclerosis Progression Front. Neurol. 12:608491. doi: 10.3389/fneur.2021.608491
Multiple sclerosis (MS) is primarily an inflammatory and degenerative disease of the central nervous system, triggered by unknown environmental factors in patients with predisposing genetic risk profiles. The prevention of neurological disability is one of the essential goals to be achieved in a patient with MS. However, the pathogenic mechanisms driving the progressive phase of the disease remain unknown. It was described that the pathophysiological mechanisms associated with disease progression are present from disease onset. In daily practice, there is a lack of clinical, radiological, or biological markers that favor an early detection of the disease's progression. Different definitions of disability progression were used in clinical trials. According to the most descriptive, progression was defined as a minimum increase in the Expanded Disability Status Scale (EDSS) of 1.5, 1.0, or 0.5 from a baseline level of 0, 1.0-5.0, and 5.5, respectively. Nevertheless, the EDSS is not the most sensitive scale to assess progression, and there is no consensus regarding any specific diagnostic criteria for disability progression. This review document discusses the current pathophysiological concepts associated with MS progression, the different measurement strategies, the biomarkers associated with disability progression, and the available pharmacologic therapeutic approaches.

Keywords: multiple sclerosis, neurodegeneration, progressive multiple sclerosis, neurofilament, MRI

\section{INTRODUCTION}

Multiple sclerosis (MS) has been classically defined as a demyelinating disease of the central nervous system (CNS), with preferential involvement of the white matter. In MS two pathological phenomena converge. There is an inflammatory event, responsible for clinical relapses and demyelination plaques in the CNS; and there is a neurodegenerative phenomenon responsible for progressive disability worsening. 
Most patients with MS have symptoms of acute/subacute focal neurological deficit, which have come to be called "relapses" or "attacks," with repetition of episodes in various locations of the CNS over time. This more frequent form of MS course is called "relapsing-remitting" (RRMS). After several years, 35$50 \%$ of patients initially classified as RRMS go into a phase characterized by slowly progressive neurological deterioration independent of previous inflammatory activity (1-4), which is commonly referred to as the "secondary progressive" phase (SPMS). Approximately $15 \%$ of patients with MS begin a slowly progressive deterioration from the start in the absence of detectable clinical relapses, a course that has been called "primary progressive" (PPMS). A fourth category, called "recurrent progressive," described those who, although initially behaving the same as patients with PPMS, develop some relapses during the course (5). This classification was revised and modified, so that the "recurrent progressive" category disappears, and activity criteria are defined, measured either by the presence of clinical relapses or activity on MRI, or by progression of disability (6).

The transition to a progressive course of the disease seems to be age-dependent. Although recent natural history studies show a lower percentage of patients transitioning from RRMS to SPMS, the age of transition is surprisingly immutable, around the forties $(4,7)$. With aging, comorbidities also play a role, and are intimately related to disability and health care resources consumption (8-10).

The neurodegenerative process, historically, was not included in the clinical diagnostic criteria of MS, with the exception of the 1965 Schumacher criteria, where two patterns of clinical involvement of MS were recognized: one with episodes of clinical deterioration separated by a month or more from each other, with a duration of at least $24 \mathrm{~h}$ (similar to the current definition of relapses), and a second pattern with a gradual clinical worsening over a period of 6 months or longer (11). In 1983, the Poser diagnosis criteria excluded progressive forms of MS, in part due to lack of reliable radiological or biological markers ruling out alternative diagnoses (i.e., progressive myelopathy or spinocerebellar syndrome) at that time (12). Although the currently recognized clinical forms of progressive MS are only defined based on clinical criteria (6), the emergence of magnetic resonance imaging (MRI) techniques allowed a better characterization of progressive MS and its differentiation between PPMS and SPMS (13). Since 2001, PPMS has been included explicitly in the McDonald criteria and its updates (14-17). Nowadays, both PPMS and SPMS are usually referred to as progressive MS (PMS).

Prevention of irreversible disability is one of the essential clinical goals in a patient with MS. However, in daily practice, there is still a lack of clinical, radiological, or biological markers that favor an early detection of the progressive course of the disease, and also there is no expert consensus on specific diagnostic criteria for disability progression (18).

\section{OBJECTIVES}

The Progression Working Group is part of the EMDAT study group (Esclerosis Múltiple Disease Activity Task Force). This is a multidisciplinary team consisting of eight neurologists (AVJ, FCPM, LBR, LFD, NTL, SEM, VML), a neuropsychologist (YH), an anatomopathologist (JFL) and a neuroradiologist (JCP) from different Health Centers in Spain, all experts in the management of patients with MS. This group aimed to elaborate a review document based on the current concepts of MS progression.

\section{MATERIALS AND METHODS}

The EMDAT Progression Working Group was divided into two subgroups with the aim to address different topics in MS progression. The first group focused on clinical and cognitive characteristics (VML, LBR, LFD, NTL, YH); the second group focused on paraclinical items: pathology, pathophysiology, and imaging markers (FCPM, AVJ, JCP, JFL, SEM). A non-systematic review document was elaborated after discussion among the participants, based on the review of the literature and the experience of each expert. The workflow for this document is detailed in Figure 1.

\section{PATHOLOGY AND PATHOPHYSIOLOGY OF PROGRESSIVE MS}

The combination of primary perivenular demyelination, loss of oligodendrocytes, inflammation, and remyelinated spots, distinguishes MS from other demyelinating disorders of the CNS (19). These features, as well as neurodegenerative changes resulting from neuronal damage, are present in all the evolutional stages of MS (20), and are always associated with B and T-cell mediated immunity, macrophages, and microglia. Lesions in MS can affect both white and gray matter of the brain and spinal cord.

The histopathological differences between relapsing and progressive forms of MS are mainly quantitative (19). Thus, relapsing MS is characterized by the predominance of confluent plaques of active demyelination, located mainly in the white matter and in areas of high venous density. They present a central inflammatory region with abundant $\mathrm{T}$ lymphocytes (especially $\mathrm{CD}^{+}$), macrophages and are associated with an accumulation of microglia. In contrast, PMS shows a higher number of slowly expanding lesions distributed in areas with less blood perfusion. Histologically these lesions present an inflammatory margin of macrophages and activated microglia that surrounds a demyelinated and inactive center. Damage to the blood-brain barrier, which is very characteristic in relapsingremitting MS (RRMS), is less evident in PMS, leading to partial compartmentalization of inflammation.

However, in other study qualitative differences and heterogeneity have been observed in MS lesions between different patients, defining a series of patterns of MS lesions (21). Normally, in the same subject, all active plaques correspond to the same pattern, although these patterns may be different 

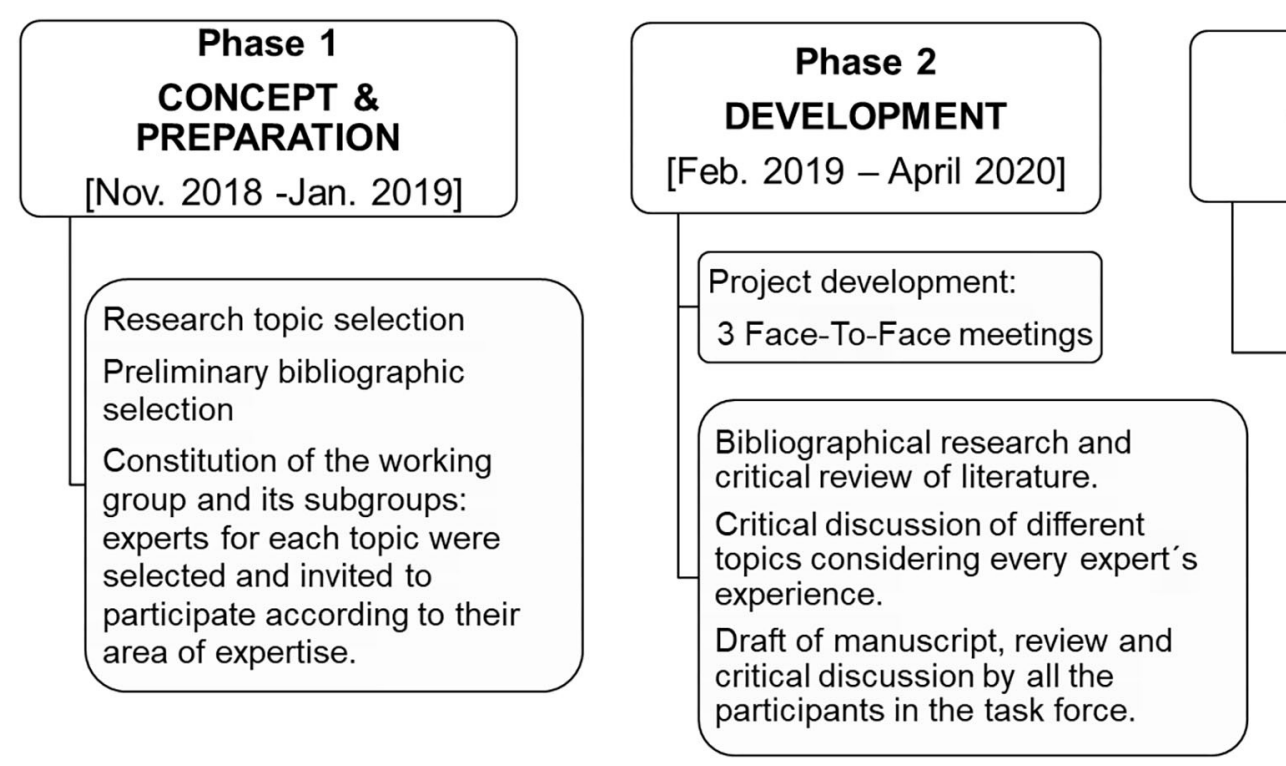

\section{Phase 3 OUTCOMES}

[May 2020]

Final version of the manuscript after consensus, including specific recommendations if appropriated.

FIGURE 1 | Overall workflow, timing, and expert group/subgroups composition.

between subjects $(21,22)$. However, other studies have not confirmed this fact, suggesting that, rather than interindividual, heterogeneity is dependent on time and the stage of evolution of the lesions in the same individual $(23,24)$. Although these differences did not clearly characterize the type of MS, it may be important to also take it into consideration.

Lesions in the gray matter predominate in PMS, especially areas of subpial cortical demyelination (25). These lesions also present inflammation, but to a lesser degree compared to white matter plaques. They can be associated with different pathological features, like ectopic lymphoid follicles, neuronal and glial cell loss, and extensive remyelination zones (26). Finally, in PMS, there is a diffuse inflammatory infiltration in the "normal-appearing" white matter, where activation of microglia, axonal damage, and reactive gliosis are seen (25).

The mechanisms that link alterations of the immune response and cerebral demyelination remain unknown. Demyelination might be associated with local microenvironmental factors or soluble factors produced by meningeal infiltrates. Demyelination could be triggered by a specific antibody, although the particular antigen targeting the myelin sheath has yet to be identified. On the other hand, genetic studies reveal activation in the oxidation of neurons, myelin, and oligodendrocytes, associated with mitochondrial damage $(27,28)$. The mitochondrial alteration would imply an energy deficit in the form of "virtual hypoxia" (29), that would amplify oxidative damage causing an imbalance in cell ion exchange through mechanisms linked to calcium channels. Finally, extracellular iron, released by injured oligodendrocytes and microglia, increases tissue susceptibility to oxidative damage caused by free radicals. All these processes may play an important role in the progressive forms of MS when cellular aging and the number of accumulated lesions exceed the brain adaptive mechanisms (30).

\section{MEASUREMENT STRATEGIES IN MS PROGRESSION}

\section{Defining Progression in MS}

In most MS clinical trials, the definition of progression is based on the increase in the Expanded Disability Status Scale (EDSS) (31) confirmed over time (18). The current concept of MS progression recommended by the European Medicines Agency (32) (Table 1), and the most widely used in clinical trials, comes from a meta-analysis of four clinical trials. Based on the patient's baseline EDSS, it establishes two different strata when defining progression. If the patient's baseline EDSS is below 6 , only $\geq 1$ point of sustained impairment is needed for progression to be considered, whereas $\geq 0.5$ points are required if baseline EDSS is higher than 6.0 (34). Later, an additional stratification of the scale was suggested, so in patients with EDSS $=0$, an increase of $\geq 1.5$ points would be needed (18), together with a major affection on the pyramidal functional system of $\geq 2$ (33).

On the other hand, there is no specific period of time for the identification of a progressive course of the MS or confirmation of its diagnosis (Table 1). This is an essential issue in the relapsing form of the disease, since the time when a patient converts to SPMS is unclear. Furthermore, during the natural course of the disease, patients in the progressive phase may continue to have relapses combined with periods of stabilization or slight clinical improvement, making thus the diagnosis more difficult (6).

It was suggested that the "transition" from the relapsing phase of the disease to the progressive one is only an artifact caused by the low sensitivity to detect minor clinical changes by the current clinical scales (35) and the brain plasticity that can compensate for clinical deficits at disease onset (36). Nevertheless, it has been proposed that the pathophysiological mechanisms associated 
TABLE 1 | Definitions used to diagnose disease progression in MS.

\begin{tabular}{|c|c|c|c|}
\hline & $\begin{array}{l}\text { Definition of progression } \\
\text { (EDSS worsening from baseline) }\end{array}$ & $\begin{array}{l}\text { Time to confirm } \\
\text { disease progression }\end{array}$ & $\begin{array}{l}\text { Population } \\
\text { studied }\end{array}$ \\
\hline $\begin{array}{l}\text { European Medicines } \\
\text { Agency (32) }\end{array}$ & $\begin{array}{l}1.0 \text { point if } E D S S \leq 5.5 \\
0.5 \text { point if } E D S S \geq 6.0\end{array}$ & 6 months & MS \\
\hline Kalincik et al. (18) & $\begin{array}{l}1.0 \text { point if } E D S S \leq 5.5 \\
0.5 \text { point if } E D S S \geq 6,0\end{array}$ & 12 or 24 months & $\begin{array}{l}\text { PMS (PPMS and } \\
\text { SPMS) }\end{array}$ \\
\hline Lorscheider et al. (33) & $\begin{array}{l}1.0 \text { point if } E D S S \leq 5.5 \\
0.5 \text { point if } E D S S \geq 6.0 \\
\text { FSS } \geq 2\end{array}$ & $\begin{array}{l}3 \text { months if basal EDSS } \\
\geq 4.0\end{array}$ & SPMS \\
\hline
\end{tabular}

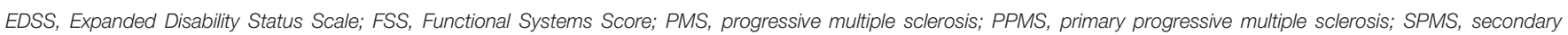
progressive multiple sclerosis.

with disease progression are probably present from the disease onset in RRMS patients, but they are often silent (37-39).

To confirm disability progression, a patient's clinical worsening should be reassessed after a variable period of time $(18,40)$. In relapsing MS, the irreversible progression of disability can be biased because of the transient deterioration associated with relapses. For this reason, it was proposed to use different clinical outcome measures to assess progression and relapses (41). The clinical improvement following a relapse usually occurs after 2 months, although recovery can occur longer than 12 months in some patients (42). For this reason, to improve sensitivity when assessing disability progression, it is suggested to evaluate patients after 1 month of clinical stability following a relapse, avoiding thus possible bias (43).

A confirmed increase in the EDSS measured at 3 or 6 months may not provide an accurate estimate of long-term disease outcomes. In this context, it was described that up to $30 \%$ of patients with a confirmed progression at 3-6 months follow up might have clinical improvements if they are reevaluated after 12-24 months, especially younger patients or if small changes in the EDSS took place (18). On the other hand, although a longer time for the disability confirmation (i.e., 12-24 months) would increase the irreversibility sensitivity, this could delay therapeutic interventions.

Recently, a novel definition of progressive MS has been proposed. It shortened the time to diagnosis in routine clinical practice (Table 1) and was introduced after comparing 576 different definitions of EMSP from a vast European registry. According to this new definition, if the patient presents with an EDSS $\geq 4$ and has a functional impairment of the pyramidal system of $\geq 2$, the clinical reassessment to confirm disability can be done during the 3 months follow up (33). Therefore, in patients with an EDSS $<4.0$, the diagnosis of irreversible disability progression should be made with caution, and a longer follow-up is suggested to safely confirm it (i.e., 6, 12, or 24 months) $(18,40)$.

\section{Physician-Oriented Measures in Progressive MS}

To date, no particular scale is considered as the gold standard to assess clinical progression in MS. Due to the high variability of MS, it seems unlikely that a single evaluation strategy will be adequate to meet all evaluation objectives in different patients. Because of this, it is necessary to use multidimensional outcome measures. Different scales would probably be required at different stages of the disease over time (41).

The EDSS is the most widely used scale in MS. Its main advantage is its familiarity, widespread use, and the information gathered on its validity and reliability (41). Although this scale is based on neurological examination and is clinically relevant, it has some disadvantages: (a) it presents an intra- and interevaluator variability that can reach up to $40 \%$ due to its low precision in distinguishing amongst mild, moderate and severe symptoms, (b) it has subjective items, such as bowel and bladder dysfunction, (c) the scale is asymmetric, assigning a relatively higher weight to patient's locomotion, and (d) the times spent in each level of the scale is variable, being higher in the upper strata $(18,41)$.

The stratification of the EDSS has been used to improve its precision in detecting progression. The presence of two strata (an increase of one point for EDSS between 0 and 5.5, or 0.5 points above EDSS of 5.5) could overestimate the progression compared to the presence of three strata (EDSS increase of 1.5 points if the baseline EDSS is 0 , an increase of one point if the baseline is between 1 and 5.5 , or increase of 0.5 points if the baseline is above 5.5). However, it must be noted that the EDSS has more stability at the highest levels of the scale and, therefore, the clinical worsening needed to consider progression would be higher. Consequently, it may be necessary to include additional assessments in patients with higher disability status to improve the progression detection sensitivity (18) since it would not measure small changes at this point (40).

The Neurostatus developed by Kappos, used in the European trial on beta-interferon-1b in the SPMS, includes a neurological examination similar to the EDSS, with extra items added to assess ambulation and vision, to improve sensitivity $(41,44)$. Nevertheless, in this evaluation, the locomotion also has a significant weight compared to the rest of the functional systems.

An international working group developed the Multiple Sclerosis Functional Composite (MSFC). It is comprised of three performance tests: 9-Hole Peg Test (9HPT) to assess upper limb function, Timed 25-Foot Walk (T25FW) to determinate ambulation, and Paced Auditory Serial Addition Test (PASAT) 
to assess cognition (45). Since the variables evaluated in these three tests are different, a $\mathrm{Z}$ score was selected as a standard metric. The MSFC is objective, multidimensional, standardized, and more sensitive in detecting clinical changes than traditional ordinal scales (41). The disadvantage of this method is related to the use of the Z-score, which orders the patient in the number of standard deviations with respect to a reference population, but does not directly translate the patient's disability status, nor is it easy to interpret changes that may occur in this score (46). However, it has been proven that a worsening of 0.5 in the total score, or $>20 \%$ in each component, is a clinically significant marker of disease progression $(47,48)$.

Composite measurements such as "EDSS-plus" have been proposed in response to the multidimensional needs of the disease (49). The aim was to improve the detection of disability progression by adding T25FW and 9HPT to the EDSS. A worsening $\geq 20 \%$ for T25FW and 9HPT, confirmed at 24 weeks, differentiates more accurately between patients who progress to PMS from those who do not. In this respect, rates of disability progression at 24 weeks measured by EDSS-Plus were $59.5 \%$, compared to only $24.7 \%$ when standard EDSS was used, suggesting that EDSS-Plus is approximately twice more sensitive than EDSS (49). On the other hand, the ORATORIO trial included the No Evidence of Progression (NEP) endpoint, which was defined as no progression in EDSS, no worsening of $\geq 20 \%$ on $9 \mathrm{HPT}$, or $\geq 20 \%$ on $\mathrm{T} 25 \mathrm{FW}$ for 12 weeks (50). In this trial, more than half of the patients who did not show a worsening of disability measured by EDSS experienced a confirmed worsening of ambulation when measured by T25FW. Also, a considerable proportion of patients who did not have a confirmed progression in EDSS, displayed a worse upper limb function when they were evaluated by using the 9HPT (50).

In conclusion, a significant change of $\geq 20 \%$ in the T25W (51), $\geq 20 \% 9$ HPT (52), or $\geq 7$-point change in the low-contrast letter acuity chart (53) should be considered progression of MS.

Finally, the use of new technologies for real-time measurement of patient disability, for example, wrist accelerometers for remote gait measurement are useful despite their limitations and will undoubtedly be applied in future clinical practice to help detect progression $(54,55)$.

\section{Patient Self-Administered Scales}

The patient-reported outcome (PRO) measures are questionnaires designed for patients to indicate their perceptions regarding their health status, quality of life, and well-being (56). Although PRO measures are not widely used in clinical practice, it has been shown that worse scores are obtained from patients with progressive forms of MS, even in the early stages of the disease (57).

The systematic use of PRO questionnaires could provide additional information on standard disability measurements for a particular patient. Considering the widespread use of digital tools, the use of different PRO tests would not necessarily increase the time spent in the neurologist office. We believe that they can be especially useful for those patients with mild disabilities or for those who complain of clinical deterioration, when that impairment cannot be confirmed with standard physicianoriented measures.

It was described that the PRO test could be used for the assessment of the MS population, based on different randomized controlled trials and observational studies (58) Taking into account different psychometric parameters, such as time of administration and neuropsychological domains to be assessed, as well as the level of the evidence supporting them, our group recommended the use of generic scales that focus on the quality of life such as the Short Form 36 (SF-36) (59) and the European Quality of Life (EQ-5D) scale (60), or specific MS scales as Multiple Sclerosis Quality of Life-54 (MSQol-54) (61). To measure the impact of the disease on the patient's motor skills and cognition, this group recommended the Multiple Sclerosis Impact Scale-29 (MSIS-29) (62). In the case where subjective gait complaints are suspected, the 12 items Multiple Sclerosis Walking Scale (MSWS12) can be used (63). Finally, to objectively assess a patient's fatigue, the Modified Fatigue Impact Scale (MFIS) can be useful (64).

There are also limitations for the PRO questionnaires since there is a lack of validation studies to support their use and no standardized cut-off points in most tests. Also, PRO questionnaires cannot be used for therapeutic decision-making since they do not allow for the confirmation of the progression of the disease.

\section{Neuropsychological Assessment}

Currently, international consensus indicates that clinical followup of the MS population should include a neuropsychological status assessment $(65,66)$. Amato et al. considered that the neuropsychological evaluation is a tool that will help to redefine the clinical activity in MS. Furthermore, it is of fundamental importance when a progression of the disease is suspected (67).

In PMS, there is a higher percentage of patients with cognitive impairment than relapsing forms of the disease $(86 \%$ in the secondary progressive and $74 \%$ in the primary progressive forms). Moreover, the severity of cognitive impairment is higher in PMS, with more cognitive domains affected by the disease (68). Compared to RRMS, in PPMS the cognitive symptoms are more prominent during disease onset, and patients have a worse cognitive decline after 6 years of follow-up (69).

Neuropsychological assessment has three aims in the clinical monitoring of the MS. First, it serves as a measurement of progression. An international consensus recommended an early baseline assessment of cognitive status of newly diagnosed patients and a follow-up reevaluation after 1 or 2 years, depending on the patient's cognitive impairment $(65,68,70)$. This assessment can be carried out by using a screening test, such as the Symbol Digit Modality Test (SDMT) (71). However, the use of a more comprehensive evaluation could provide more information regarding other neuropsychological domains, such as cognitive, emotional, and behavioral processes $(65,66)$. The second aim is to predict cognitive impairment. Studies showed that patients with untimely cognitive impairment are more likely to develop earlier the secondary progressive form of the disease (72). Also, in newly diagnosed patients, alterations in memory and speed of information processing predict physical disability as 
measured by EDSS at 5 and 7 years (73). Mood disorders during disease onset (i.e., depression or anxiety) also serve as predictors of cognitive changes after 1 year of follow-up (74). Physical fatigue in early phases is related with a rise in disability degree 3 years later. Accordingly, an increase of 10 points in the Fatigue Impact Scale would indicate clinical deterioration (75). The third aim is to certify the progression of the disease. It has been established that a reduction of $\geq 4$ points or a $10 \%$ worsening in the Symbol Digit Modality Test without concomitant depression or fatigue, can be considered clinical deterioration (76). However, the patient's cognitive impairment must be confirmed during the follow-up evaluations. It has not yet been defined how long for is necessary to maintain the cognitive deterioration for the disease progression to be classified as irreversible.

\section{BIOMARKERS ASSOCIATED WITH DISABILITY PROGRESSION}

\section{Imaging Biomarkers: Magnetic Resonance Imaging (MRI)}

In progressive MS, the MRI facilitates the demonstration of the substrate of disease progression (i.e., demyelination, axonal degeneration, and microglial activation), predicting thus future disability, and exploring new parameters of treatment efficacy (77). However, the role of MRI in progressive MS regarding diagnostic and monitoring of progression is currently limited (78) (Table 2).

\section{MRI Findings Associated With Neuroinflammation}

The baseline lesion burden in the CNS and the increase in the number of T2 lesions during the follow-up studies are good predictors of both short and long-term cumulative disability (80). The specific localization of T2 lesions in the brain and spinal cord is also crucial in predicting progression. In the early stages of the disease, lesions located in the cerebellum, pons, or midbrain correlate well with a higher risk of future cumulative disability (81). Also, the presence of spinal cord lesions at the initial stages of the RRMS forms has been described as a robust predictor of progression and cumulative disability 15 years after the diagnosis (82).

Slowly expanding lesions (SEL) lie halfway between neuroinflammation and neurodegeneration. They are more frequent in progressive forms of the disease and correspond to active chronic lesions without alteration of the blood-brain barrier. The use of semi-automatic programs to quantify their growth can help with their identification (83). The use of specific sequences permits the identification of iron-laden microglia/macrophages in their periphery (84). The presence of multiple SELs is associated with more aggressive forms of the disease, with shorter intervals between onset and progressive phase of the disease, and a higher motor and cognitive disability (85). In the future, the evaluation of the peripheral edges of the SEL could also be useful to evaluate treatment efficacy (86).

Cortical gray matter lesions are present in all forms of MS but are more frequent in the progressive forms. In the relapsing form of the disease, the basal cortical lesion load and its evolutional accumulation are associated with disability and cognitive impairment at 5 years $(87,88)$. Spinal cord gray matter involvement is more frequent in PMS patients and is independently associated with disability progression (89).

The presence of asymptomatic gadolinium-enhanced lesions in the basal MRI is associated with shorter time to PMS phase progression and with worse physical and mental impairment (82).

Leptomeningeal infiltrates are markers of inflammation in different MS subtypes and correspond to ectopic lymphoid follicular structures that lead to cortical damage with demyelination and axonal loss. They are more prevalent in the PMS form and correlate well with cortical atrophy and worse disability at 5 years (84). Meningeal enhancement patterns can be variable and depending on the type and persistence over time, there may be a more significant correlation with the disability deterioration (90).

\section{MRI Findings Associated With Neurodegeneration}

Chronic black holes are hypointense lesions in T1-weighted sequences that persist for more than 6 months (91). The number of black holes at disease onset and its subsequent progression predicts future worsening of disability measured with EDSS (85).

Cerebral atrophy is described in all MS phenotypes, with a progression of the atrophy of $0.5-1.3 \%$ per year usually. The cerebral atrophy is one of the objective parameters that have the highest correlation with disease progression at 10 years and correlates with deterioration of the cognitive function (81). Its application in daily clinical practice is difficult due to the multiple confounding factors that can alter its calculation (92). Globally, the level of brain atrophy at disease onset is associated with a more significant future cognitive decline, fatigue, and disability. Finally, the assessment of brain atrophy has been included in clinical trials as a marker of treatment efficacy (85).

Gray matter atrophy is greater in progressive forms of the disease and correlates well with clinical disability. There are differences in the location of the atrophy depending on the clinical form; in SPMS temporal cortex atrophy is more evident $(84,93)$. Thalamus atrophy in recently diagnosed patients is associated with an increased risk of disability progression and cognitive impairment $(78,84)$. On the other hand, cortical atrophy of the cerebellar lobes is correlated with cognitive impairment in patients with PMS (78).

Finally, the spinal cord atrophy, measured in the cervical segment, is more significant in the progressive phase and has a strong correlation with disability (94). Furthermore, the evolutional loss of spinal cord volume is an independent marker associated with disease progression (95). Finally, the spinal cord atrophy is a potential biomarker of the efficacy of new drugs but lacks reproducibility across patient populations (94).

\section{Advanced MRI Techniques in Clinical Practice}

Functional magnetic resonance imaging studies have shown changes in the cortex of patients with PPMS. These changes involve alterations in function of neural networks. The alterations 
TABLE 2 | MRI sequences useful to predict disability and progression in MS.

\begin{tabular}{|c|c|c|}
\hline Sequence* & $\begin{array}{l}\text { Useful findings in impairment prediction and disease } \\
\text { progression }\end{array}$ & $\begin{array}{l}\text { Technical considerations and } \\
\text { limitations }\end{array}$ \\
\hline T2, PD, FLAIR & $\begin{array}{l}\text { - Initial lesion load and appearance of new lesions in baseline studies } \\
\text { - Topography of lesions (i.e., protuberance, midbrain, and spinal cord) }\end{array}$ & \\
\hline DIR, 3D T1, MPRAGE/MP2RAGE & $\begin{array}{l}\text { - Greater detection of cortical lesions in baseline study and their } \\
\text { increase in number with evolution. }\end{array}$ & \\
\hline PSIR & $\begin{array}{l}\text { - Superior detection of cortical lesions and their increase in number } \\
\text { with evolution. } \\
\text { - Higher detection of spinal cord lesions } \\
\text { - Detection of spinal cord gray matter involvement. }\end{array}$ & \\
\hline \multirow[t]{2}{*}{ 3D T1 } & $\begin{array}{l}\text { BRAIN: } \\
\text { - Global cerebral atrophy } \\
\text { - Cortical atrophy } \\
\text { - Deep gray matter atrophy (thalamus/caudate nucleus). } \\
\text { - Chronic black holes detection } \\
\text { - Slowly expanding lesions (SEL). }\end{array}$ & $\begin{array}{l}\text { - Difficult application in clinical practice: } \\
\text { multiple confounding factors can alter its } \\
\text { calculation. } \\
\text { - Isometric voxels with } 1 \times 1 \times 1 \mathrm{~mm} \\
\text { resolution } \\
\text { - Use of automatic or semiautomatic post- } \\
\text { processing tools. } \\
\text { - Use of segmentation techniques. }\end{array}$ \\
\hline & $\begin{array}{l}\text { SPINAL CORD: } \\
\text { - Global spinal cord atrophy (measurement in the cervical segment). }\end{array}$ & - Poor reproducibility \\
\hline \multirow[t]{2}{*}{$\mathrm{T}^{*}$ and $\mathrm{SWI}$} & $\begin{array}{l}\text { - Number of SEL with peripheral iron rim due to the presence } \\
\text { of microglia/macrophages }\end{array}$ & $\begin{array}{l}\text { - High magnetic fields (3T and } 7 \mathrm{~T}) \text {. } \\
\text { - Phase imaging }\end{array}$ \\
\hline & - Assessment of iron deposition in basal ganglia & $\begin{array}{l}\text { - Quantitative evaluation with R2* } \\
\text { mapping or QSM }\end{array}$ \\
\hline 3D-T2-FLAIR post contrast & - Detection of ectopic lymphoid follicles. & $\begin{array}{l}\text { - Late acquisition at } 10-15 \text { min. } \\
\text { - Subtracted images }\end{array}$ \\
\hline MTI & $\begin{array}{l}\text { Magnetization transfer ratio (MTR): } \\
\text { - MTR reduction in ANWM, ANGM, and T2 lesions. }\end{array}$ & $\begin{array}{l}\text { - Used in clinical trials to monitor } \\
\text { myelin integrity }\end{array}$ \\
\hline Spectroscopy & - Assessment of NAA (N-acetyl-aspartate) levels. & - No conclusive results \\
\hline DTI & - Alteration of fractional anisotropy (FA) values & - No conclusive results \\
\hline
\end{tabular}

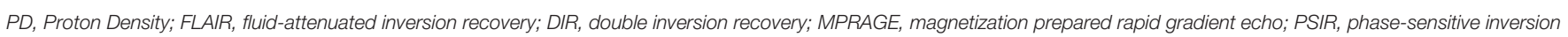
recovery; SWI, susceptibility-weighted imaging; QSM, quantitative susceptibility mapping; MTI, Magnetization Transfer Imaging; DTI, diffusion tensor imaging.

detected could suggest that the cortical adaptation capacity to adapt to tissue damage in patients with progressive forms of MS would also be altered, contributing to functional loss (96).

The Magnetization Transfer Ratio (MTR) is a measurement of tissue integrity. Alteration of its values in apparently normal white matter (ANWM) is more significant in PPMS and SPMS phenotypes. Low initial MTR values in ANWM can predict severe impairment and disability in PPMS. MTR has been used in clinical trials to study tissue remyelination in patients with SPMS (78).

DTI (Diffusion Tensor Imaging) can be used to measure demyelination and axonal loss in T2 lesions, in ANWM and gray matter. The alteration of the anisotropy fraction has been correlated with a physical and cognitive disability (97).

Magnetic resonance spectroscopy studies observed decreased levels of $\mathrm{N}$-acetyl-aspartate (NAA) in both evolving lesions and ANWM and, interestingly, in the cortex of patients with progressive forms $(78,98)$.

Quantification of iron deposition in basal ganglia has been shown to correlate well with cognitive decline. It has also been proposed as a marker of future cumulative disability in patients with a clinically isolated syndrome $(99,100)$.

\section{Neurophysiological Biomarkers}

Although the role of neurophysiological tests, as evoked potentials (EP), has been displaced in the last updates of diagnostic criteria in both relapsing and primary progressive MS, there are several studies that have investigated their potential role in predicting disability or even treatment response, and are still a useful paraclinical diagnostic support for MS, enhancing the detection of clinical unapparent demyelinating lesions (101). EP not only assess CNS conductions, being an objective ancillary evaluation of visual, motor (pyramidal), sensory and acoustic pathways, but also can have a glimpse on intracortical processes that are related to the mechanisms of brain plasticity (102).

\section{Serum and CSF Biomarkers}

The search for new biomarkers in multiple sclerosis is necessary for the early diagnosis of the disease, to stratify risk, to predict and monitor progression, to measure treatment response, and to monitor adverse drug effects (103). There are currently a few validated useful biomarkers to predict MS progression, but research in this field has been multiplied in recent years.

One of the essential biomarkers in MS is the oligoclonal bands (OCB). The presence of OCB in the cerebrospinal fluid in patients 
with a clinically isolated syndrome is an independent predictive factor for moderate disability (EDSS 3.0) in the future (80). Also, intrathecal secretion of IgG has been associated with increased risk of worsening disability in a shorter time (104).

Other CSF molecules have been studied, such as CXCL13 chemokine, which is associated with increased disability in MS patients, but is not specific, and correlates with BOCs (105). The glial fibrillary acidic protein (GFAP) is an intermediate filament protein associated with astrocyte damage and astrogliosis. This protein has been associated with severe disability progression after 8-10 years of disease evolution and is higher in PMS (106, 107). It also correlates with the glycoprotein YKL-40 (CHI3L1), a biomarker associated with progression to EDSS of 6.0 (108).

Neurofilament light chains (NfL) are biomarkers of neuronal damage found in both CSF and serum. In CSF, measured by ELISA, they have been proposed as predictors of severity and disease progression. Higher levels of NfL have been found in patients who switched to the PMS form (109). In a recent prospective study of 607 patients over 12 years in which serum NfL was measured using Simoa assay, a significant relationship was found between EDSS deterioration and NfL serum levels. However, no association was found between serum NFL levels and long-term disease progression in relapsing and between CSF NFL levels and EDSS scores in primary progressive forms $(110,111)$. These results are contradictory to those found by Barro and Disanto in two different studies, where a correlation was found between high serum NfL levels and long term disability progression in MS $(112,113)$. A recent meta-analysis of NFL in progressive MS also points out that NFL are more related to acute inflammation rather than being able to differentiate prognosis in progressive MS (114).

\section{Additional Imaging Biomarkers}

Optical coherence tomography (OCT) is an imaging technique that has been used to evaluate retinal integrity in MS patients. Peripapillary retinal nerve fiber layer (pRNFL) and ganglion cell-inner plexiform layer (GCIPL) thickness are recognized as markers of diffuse axonal damage in MS $(115,116)$.

Few studies have analyzed the role of OCT in patients with progressive forms of MS. Most of these studies are cross-sectional and include heterogeneous populations, in which PMS patients constitute only a small proportion of the studied cohorts.

Other studies demonstrated that pRNFL and GCIPL thinning correlates with a higher EDSS $(115,116)$. Also, it was proved that the OCT could be useful in predicting disability progression during follow-up. Specifically, the authors of this work demonstrated that presentation with a pRNFL thickness below 88 um confers a higher risk of developing disability after 5 years of follow-up (HR 1.96, 95\% CI 1.39-2.76) (117). An independent study also demonstrated that a thickness of RNFL below $88 \mathrm{um}$ is associated with an increased risk of developing cognitive impairment as well, measured by the SDMT (118).

It is worth mentioning that these two studies have been performed in relapsing MS patients, and it is not known whether these results can be extrapolated to progressive forms of the disease.

\section{PHARMACOLOGICAL TREATMENT FOR PROGRESSIVE FORMS}

Different drugs have been tested in progressive forms of MS (Table 3). However, most of the clinical trials have shown negative results, probably because of erroneous pharmacological targets, or the strategies used to measure disease progression (79).

\section{Why Do Most Therapeutic Strategies Fail in Progressive Forms of MS?}

The main reason that the majority of drugs tested so far failed to control the progressive phase of the disease is because of the inability to reverse the pathophysiological mechanism responsible for progression (119). The therapeutic options available for progressive MS are insufficient, which continues to be a significant challenge for researchers (120). In PMS, it was stated that inflammation might be partly compartmentalized in the brain, and the intact blood-brain barrier prevents the migration of the drugs into the CNS, limiting thus their effect (120).

The SPMS form may still be associated with slight clinical disease activity. On the other hand, the effects that most of the current disease-modifying treatments (DMT) exert are predominately on the inflammatory phase of the disease (121). Hence, in clinical trials of PMS, some treatments reached their best results in the subgroups of patients with slight disease activity or shorter times of evolution (122-124). Table 4 shows the currently approved treatments for PMS.

There are many drugs that have failed in their clinical trials in the treatment of PMS, and their treatment continues to be a challenge today (120). The causes of these failures are diverse.

The most obvious cause, as it is mentioned before, is that the drugs used in clinical trials have not been able to reverse or to stop the pathogenic mechanisms of the disease (119). In PMS, inflammation might be partly compartmentalized within the CNS, and the intact blood-brain barrier prevents the migration of drugs into the CNS, limiting thus their effect (120). Sometimes the criteria for deciding that a molecule could work in a PMS clinical trial is its success in a previous clinical trial in relapsing forms of MS, and this may not be extrapolated to PMS (46).

Other reason at stake could be an inappropriate clinical trial design, outcome, sample size or population. As an example, interferon beta in SPMS has inconsistently showed efficacy for preventing progression in patients with SPMS. These inconsistencies between clinical trials seem to be mostly related to differences in previous inflammatory disease activity between populations, rather to a real effect over the degenerative process. A systematic review of the clinical trials in SPMS pointed out to younger patients and those with pre-treatment relapses having better outcomes than older patients with longer disease duration and those who did not experience pre-study relapses (130). On the other side, two trials with interferon beta failed to show a reduction in disability progression in PPMS patients (131, 132). However, the trial populations were too small to allow definitive conclusions on the efficacy of interferon beta treatment in patients with PPMS (133). 
TABLE 3 | Clinical trials in progressive MS. Adapted from Ciotti JR and Cross AH (79).

\section{Tested drug}

\section{Type of MS}

\section{MECHANISM OF ACTION: NON-SELECTIVE IMMUNOSUPPRESSANTS}

Cyclophosphamide $750 \mathrm{mg} / \mathrm{m}^{2}$

vs. IV glucocorticoids

Sulfasalazine 500-2,000 mg daily vs. placebo

Mitoxantrone 5 or $12 \mathrm{mg} / \mathrm{m}^{2}$ q3

months vs. placebo

Cladribine 0.7 or $2.1 \mathrm{mg} / \mathrm{kg}$ (total

dose over course) vs. placebo

\section{MECHANISM OF ACTION: IMMUNOMODULATORS}

IFN beta 1-b 8 million IU every

trial)

IFN beta 1-b 250 or 160 mcg

every other day vs. placebo

(American trial)

IFN beta 1-a 22 mcg, 44 mcg vs.

placebo (SPECTRIMS)

IFN beta 1-b 8 MUI every other

day vs. placebo

IFN beta 1-a 60 mcg q Weekly

vs. placebo (IMPACT)

Glatiramer acetate $20 \mathrm{mg}$ daily

vs. placebo

Laquinimod $0.6 \mathrm{mg}$ daily vs.

placebo

\section{MONOCLONAL ANTIBODY}

Rituximab 1,000 mg q6 months

vs. placebo

Natalizumab 300 mg IV q4

weeks vs. placebo

Ocrelizumab 600 mg q6 months

vs. placebo

Opicinumab 3 or 10 or 30 or 100 $\mathrm{mg} / \mathrm{kg}$ every 4 weeks + IFN beta

SPMS

SPMS

SPMS

PPMS

PPMS

PPMS

SPMS

PPMS

SPMS other day vs. placebo (European

\section{Number of}

subjects

SPMS

RRMS,

SPMS, PPMS

PRMS, SPMS

SPMS, PPMS

Primary endpoint

Results

Time to

Time to progression (using EDSS)

Sequentially tested endpoints in ambulation, relapses, time to first relapse, and changes in SNS

Mean change in EDSS

Failure
Duration 1-a vs. placebo +IFN beta $1 \mathrm{a}$

PPMS, SPMS

RRMS, active

Siponimod 0.25-2 mg vs.

placebo

Fingolimod $0.5 \mathrm{mg}$ or $1.25 \mathrm{mg}$

daily vs. placebo

SPMS

PPMS

\section{MECHANISM OF ACTION: NEUROPROTECTOR}

Ibudilast $100 \mathrm{mg}$ daily vs.

placebo (added to patient's

immunomodulator treatment)

Biotin $300 \mathrm{mg}$ daily vs. placebo

(added to patient's

immunomodulator treatment)
SPMS, PPMS

SPMS, PPMS

\section{MECHANISM OF ACTION: SELECTIVE IMMUNOSUPPRESSANTS}

159

138

199

194

718

939

2 years
3 years
1.5 years

1 year

1,5 years

3 years

618

73

3 years

2 years

2 years

3 years

1 year

374

439

889

2 years

732

418

1651

970

255

154
Confirmed progression of disability measured by EDSS

$p=0.007$

Confirmed progression of

Failure

Confirmed progression of disability measured by EDSS

EDSS

Failure

Failure

MSFC

Time to EDSS worsening

Failure

Percentage of change in brain volume

Failure

Time to EDSS worsening

Failure

$p=0.013$

Proportion of disability improvement (EDSS and T25FW) were change in EDSS, changes disability measured by EDSS

$p=0.003$
2 years

3 years

1.5 years

.

3 years

5 years

2 years

Percentage of patients with progression in EDSS, T25FW or 9HPT

Percentage of patients with progression in EDSS

Percentage of patients with improvements in EDSS, T25FW, 9HPT O PASAT

Confirmed progression of disability measured by EDSS

Time to progression measured by EDSS, T25FW, or 9HPT

Failure

Change in brain volume assessed by BPF

$p=0.04$

Failure

$p=0.03$

Failure

1 year

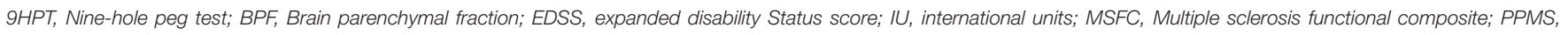
primary progressive multiple sclerosis; PRMS, progressive relapsing multiple sclerosis; RRMS, relapsing-remitting multiple sclerosis; SNS, standardized neurological status; SPMS, secondary progressive multiple sclerosis; T25FW, timed 25-foot walk. 
TABLE 4 | Approved treatments for progressive MS (125-129).

\begin{tabular}{ll}
\hline Drugs & $\begin{array}{l}\text { Indications approved by European } \\
\text { Medicines Agency }\end{array}$ \\
\hline $\begin{array}{l}\text { Interferon beta 1-b sc } \\
\text { Interferon beta 1-a sc }\end{array}$ & Relapsing SPMS \\
Mitoxantrone & Highly active relapsing MS, associated \\
& with a rapid evolution of disability in which \\
there are no alternative therapeutic & options. \\
Active PPMS & Relapsing SPMS \\
Ocrelizumab & Recently FDA and EMA approved for \\
Siponimod & active SPMS \\
\hline
\end{tabular}

EMA, European Medicines Agency; FDA, Food and Drugs Administration; SPMS, secondary progressive multiple sclerosis; sc, subcutaneous; MS, multiple sclerosis.

Another example applies to the trial of fingolimod for PPMS, in which more than $40 \%$ of patients were 50 or more years of age, and more than $85 \%$ had no contrast-enhanced lesions (134). The tools for measuring progression may not be sensitive enough to detect progression, the primary objectives may not be the most appropriate, as well as the length of the trials, too short for PMS (135). In the ASCEND trial (natalizumab vs. placebo in SPMS), the results were negative for the primary endpoint and for the T25FW as secondary endpoint. However, an effect on the 9HPT was observed as secondary outcome (136). This latter study in SPMS contrasts with the moderate but positive effect of siponimod, a selective sphingosine-1-phosphate receptors 1 and 5 modulator, on disability progression in SPMS. As in the ASCEND trial, the clinical benefit of siponimod was more evident in upper extremity function (9HPT) than in lower extremity function (T25FW) (122).

The failure of the OLYMPUS trial with rituximab (124) can be partly attributed to a miscalculation of the sample size, probably due to a false expectation of progression rate from the placebo group. This highlights the importance of adequate planning prior to the study and of gathering more information to infer the probability of progression in the placebo group. The ORATORIO design was able to overcome these problems that arose in the OLYMPUS clinical trial $(133,137)$. Long-term effects of ocrelizumab in PPMS have been observed with sustained benefit through 6.5 years of follow-up (138).

\section{Therapeutic Failure in Progressive Forms}

There is no consensus on the definition of therapeutic failure in progressive forms of the MS. Persistence or appearance of new activity, either radiological or clinical, should be considered as a therapeutic failure. However, in the absence of inflammatory activity, measuring progression can be more complex. In PMS, EDSS has limited value in capturing slight changes in clinical status, and should probably be complemented by other scales such as T25FW and 9HPT. An alternative option might be to consider the No Evidence of Progression or Active Disease
(NEPAD), which is a combined outcome measure used in a clinical trial in patients with PPMS. It includes the absence of progression and takes into account relapses and MRI activity, which can both be present during the progressive phase (50).

On the other hand, DMT modulate the evolution of the disease. However, we cannot confirm that they can stop its progression. Thus, it is expected that patient will progress during the disease course over time, despite responding to DMT at disease onset. This point leads to another question: should we maintain treatments indefinitely or should we stop it after a certain level of disability is reached? In this respect, the American Academy of Neurology guidelines suggest to consider withdrawing DMT in patients with EDSS $\geq 7.0$ in the absence of clinical or radiological activity (139), although this proposal is pending validation.

\section{CONCLUSIONS}

The progression prevention of irreversible disability is the primary therapeutic objective for every neurologist in the management of patients with MS. Despite this, the definition of progression remains controversial, as well as its clinical and radiological identification in daily practice.

The clinical definitions of disability progression are based on the increase in EDSS over a specific time, making it necessarily retrospective. This means that nowadays, early identification of progression is challenging, but it would be desirable to take useful therapeutic actions for the patients. The different examination scales used in clinical practice, despite having significant advantages, can be deficient if used in isolation. Due to the multidimensional characteristics of the disease, composite measures, such as EDSS plus, could precisely identify progression as quickly as possible.

The search for biomarkers that help identify progression in MS is essential. MRI mainly offers prognostic factors but does not allow us to identify progression when it occurs. There are few validated biomarkers available for MS progression. Research in this field has been multiplied in recent years.

Pharmacotherapy in progressive forms is currently very limited. The pathophysiology of the disease may be responsible for the repeated failure of various molecules to prevent progression. Pharmacotherapy, along with the early identification of progression, is one of the significant challenges in progressive multiple sclerosis.

\section{AUTHOR CONTRIBUTIONS}

VM-L and FP-M conceptualized, designed and supervised the review, contributed the specific topics, revised the manuscript for intellectual content, and acted as co-coordinators. LB-R, JC-P, SE-M, JF-L, LF, YH, NT, and AV-J contributed the specific topics and assisted in drafting and revising the final version of the manuscript. All authors read and approved the final manuscript. 


\section{REFERENCES}

1. Confavreux C, Vukusic S, Adeleine P. Early clinical predictors and progression of irreversible disability in multiple sclerosis: an amnesic process. Brain. (2003) 126:770-82. doi: 10.1093/brain/awg081

2. Leray E, Yaouanq J, Le Page E, Coustans M, Laplaud D, Oger J, et al. Evidence for a two-stage disability progression in multiple sclerosis. Brain. (2010) 133:1900-13. doi: 10.1093/brain/awq076

3. Scalfari A, Lederer C, Daumer M, Nicholas R, Ebers G, Muraro P. The relationship of age with the clinical phenotype in multiple sclerosis. Mult Scler. (2016) 22:1750-8. doi: 10.1177/1352458516630396

4. Coret F, Pérez-Miralles FC, Gascón F, Alcalá C, Navarré A, Bernad A, et al. Onset of secondary progressive multiple sclerosis is not influenced by current relapsing multiple sclerosis therapies. Mult Scler J Exp Transl Clin. (2018) 4:2055217318783347. doi: 10.1177/2055217318783347

5. Lublin FD, Reingold SC. Defining the clinical course of multiple sclerosis: results of an international survey. National Multiple Sclerosis Society (USA) Advisory Committee on Clinical Trials of New Agents in Multiple Sclerosis. Neurology. (1996) 46:907-11. doi: 10.1212/WNL.46.4.907

6. Lublin FD, Reingold SC, Cohen JA, Cutter GR, Sorensen PS, Thompson AJ, et al. Defining the clinical course of multiple sclerosis: The 2013 revisions. Neurology. (2014) 83:278-86. doi: 10.1212/WNL.0000000000000560

7. Zeydan B, Kantarci OH. Progressive forms of multiple sclerosis: distinct entity or age-dependent phenomena. Neurol Clin. (2018) 36:163-71. doi: 10.1016/j.ncl.2017.08.006

8. Petruzzo M, Reia A, Maniscalco GT, Luiso F, Lanzillo R, Russo CV, et al. The Framingham cardiovascular risk score and 5-year progression of multiple sclerosis. Eur J Neurol. (2021) 28:893-900. doi: 10.1111/ene. 14608

9. Ostolaza A, Corroza J, Ayuso T. Multiple sclerosis and aging: comorbidity and treatment challenges. Mult Scler Relat Disord. (2021) 50:102815. doi: 10.1016/j.msard.2021.102815

10. Cisternas M, Bartolome L, Gitar B, Hulbert E, Trenz H, Patel V, et al. Health care resource utilization and disease modifying treatment use in multiple sclerosis patients by age and insurance type. Curr Med Res Opin. (2021). doi: 10.1080/03007995.2021.1885367. [Epub ahead of print].

11. Schumacker GA, Beebe G, Kibler RF, Kurland LT, Kurtzke JF, McDowell F, et al. Problems of experimental trials of therapy in multiple sclerosis: report by the panel on the evaluation of experimental trials of therapy in multiple sclerosis. Ann N Y Acad Sci. (1965) 122:55268. doi: 10.1111/j.1749-6632.1965.tb20235.x

12. Poser CM, Paty DW, Scheinberg L, McDonald WI, Davis FA, Ebers GC, et al. New diagnostic criteria for multiple sclerosis: guidelines for research protocols. Ann Neurol. (1983) 13:227-31. doi: 10.1002/ana.410130302

13. Thompson AJ, Kermode AG, Wicks D, MacManus DG, Kendall BE, Kingsley DPE, et al. Major differences in the dynamics of primary and secondary progressive multiple sclerosis. Ann Neurol. (1991) 29:5362. doi: 10.1002/ana.410290111

14. McDonald WI, Compston A, Edan G, Goodkin D, Hartung HP, Lublin FD, et al. Recommended diagnostic criteria for multiple sclerosis: guidelines from the International Panel on the diagnosis of multiple sclerosis. Ann Neurol. (2001) 50:121-7. doi: 10.1002/ana.1032

15. Polman CH, Reingold SC, Edan G, Filippi M, Hartung H-P, Kappos L, et al. Diagnostic criteria for multiple sclerosis: 2005 revisions to the "McDonald Criteria”. Ann Neurol. (2005) 58:840-6. doi: 10.1002/ana.20703

16. Polman CH, Reingold SC, Banwell B, Clanet M, Cohen J a., Filippi M, et al. Diagnostic criteria for multiple sclerosis: 2010 Revisions to the McDonald criteria. Ann Neurol. (2011) 69:292-302. doi: 10.1002/ana.22366

17. Thompson AJ, Banwell BL, Barkhof F, Carroll WM, Coetzee T, Comi G, et al. Diagnosis of multiple sclerosis: 2017 revisions of the McDonald criteria. Lancet Neurol. (2018) 17:162-73. doi: 10.1016/S1474-4422(17)30470-2

18. Kalincik T, Cutter G, Spelman T, Jokubaitis V, Havrdova E, Horakova D, et al. Defining reliable disability outcomes in multiple sclerosis. Brain. (2015) 138:3287-98. doi: 10.1093/brain/awv258

19. Lassmann H. Multiple Sclerosis Pathology. Cold Spring Harb Perspect Med. (2018) 8:a028936. doi: 10.1101/cshperspect.a028936

20. Haider L, Zrzavy T, Hametner S, Höftberger R, Bagnato F, Grabner G, et al. The topograpy of demyelination and neurodegeneration in the multiple sclerosis brain Brain Advance Access. Brain. (2016) 139:80715. doi: 10.1093/brain/awv398

21. Lucchinetti C, Brück W, Parisi J, Scheithauer B, Rodriguez M, Lassmann H. Heterogeneity of multiple sclerosis lesions: implications for the pathogenesis of demyelination. Ann Neurol. (2000) 47:70717. doi: 10.1002/1531-8249(200006)47:6<707::AID-ANA3>3.0.CO;2-Q

22. Metz I, Weigand SD, Popescu BFG, Frischer JM, Parisi JE, Guo Y, et al. Pathologic heterogeneity persists in early active multiple sclerosis lesions. Ann Neurol. (2014) 75:728-38. doi: 10.1002/ana.24163

23. Barnett $\mathrm{MH}$, Prineas JW. Relapsing and remitting multiple sclerosis: Pathology of the newly forming lesion. Ann Neurol. (2004) 55:45868. doi: 10.1002/ana.20016

24. Breij ECW, Brink BP, Veerhuis R, van den Berg C, Vloet R, Yan R, et al. Homogeneity of active demyelinating lesions in established multiple sclerosis. Ann Neurol. (2008) 63:16-25. doi: 10.1002/ana.21311

25. Kutzelnigg A, Lucchinetti CF, Stadelmann C, Brück W, Rauschka H, Bergmann M, et al. Cortical demyelination and diffuse white matter injury in multiple sclerosis. Brain. (2005) 128:2705-12. doi: 10.1093/brain/awh641

26. Peterson JW, Bö L, Mörk S, Chang A, Trapp BD. Transected neurites, apoptotic neurons, and reduced inflammation in cortical multiple sclerosis lesions. Ann Neurol. (2001) 50:389-400. doi: 10.1002/ana.1123

27. Fischer MT, Wimmer I, Höftberger R, Gerlach S, Haider L, Zrzavy T, et al. Disease-specific molecular events in cortical multiple sclerosis lesions. Brain. (2013) 136:1799-815. doi: 10.1093/brain/awt110

28. Mahad D, Ziabreva I, Lassmann H, Turnbull D. Mitochondrial defects in acute multiple sclerosis lesions. Brain. (2008) 131:1722-35. doi: 10.1093/brain/awn105

29. Trapp BD, Stys PK. Virtual hypoxia and chronic necrosis of demyelinated axons in multiple sclerosis. Lancet Neurol. (2009) 8:280-91. doi: 10.1016/S1474-4422(09)70043-2

30. Lassmann $H$, van Horssen J, Mahad D. Progressive multiple sclerosis: pathology and pathogenesis. Nat Rev Neurol. (2012) 8:647-56. doi: $10.1038 /$ nrneurol.2012.168

31. Kurtzke JF. Rating neurologic impairment in multiple sclerosis: an expanded disability status scale (EDSS). Neurology. (1983) 33:144452. doi: 10.1212/WNL.33.11.1444

32. European Medicines Agency. Clinical Investigation of Medicinal Products for the Treatment of Multiple Sclerosis (2015). Available online at: https:// www.ema.europa.eu/en/documents/scientific-guideline/guideline-clinicalinvestigation-medicinal-products-treatment-multiple-sclerosis_en-0.pdf (accessed September 20, 2020).

33. Lorscheider J, Buzzard K, Jokubaitis V, Spelman T, Havrdova E, Horakova D, et al. Defining secondary progressive multiple sclerosis. Brain. (2016) 139:2395-405. doi: 10.1093/brain/aww173

34. Weinshenker BG, Issa M, Baskerville J. Meta-analysis of the placebo-treated groups in clinical trials of progressive MS. Neurology. (1996) 46:16139. doi: 10.1212/WNL.46.6.1613

35. Rudick RA, Kappos L. Measuring disability in relapsing-remitting MS. Neurology. (2010) 75:296-7. doi: 10.1212/WNL.0b013e3181ecf815

36. Roosendaal SD, Schoonheim MM, Hulst HE, Sanz-Arigita EJ, Smith $\mathrm{SM}$, Geurts JJG, et al. Resting state networks change in clinically isolated syndrome. Brain. (2010) 133:1612-21. doi: 10.1093/brain/ awq058

37. Paz Soldan MM, Novotna M, Abou Zeid N, Kale N, Tutuncu M, Crusan DJ, et al. Relapses and disability accumulation in progressive multiple sclerosis. Neurology. (2015) 84:81-8. doi: 10.1212/WNL.0000000000 001094

38. Cree BAC, Hollenbach JA, Bove R, Kirkish G, Sacco S, Caverzasi E, et al. Silent progression in disease activity-free relapsing multiple sclerosis. Ann Neurol. (2019) 85:653-66. doi: 10.1002/ana.25463

39. Gil-Perotin S, Alcalá C, Pérez-Miralles FC, Casanova B. Silent progression or bout onset progressive multiple sclerosis? Ann Neurol. (2019) 86:4722. doi: $10.1002 /$ ana. 25537

40. Ebers GC, Heigenhauser L, Daumer M, Lederer C, Noseworthy JH. Disability as an outcome in MS clinical trials. Neurology. (2008) 71:62431. doi: 10.1212/01.wnl.0000313034.46883.16

41. Amato MP, Portaccio E. Clinical outcome measures in multiple sclerosis. $J$ Neurol Sci. (2007) 259:118-122. doi: 10.1016/j.jns.2006.06.031 
42. Hirst CL, Ingram G, Pickersgill TP, Robertson NP. Temporal evolution of remission following multiple sclerosis relapse and predictors of outcome. Mult Scler. (2012) 18:1152-8. doi: 10.1177/1352458511 433919

43. Kappos L, Butzkueven H, Wiendl H, Spelman T, Pellegrini F, Chen Y, et al. Greater sensitivity to multiple sclerosis disability worsening and progression events using a roving versus a fixed reference value in a prospective cohort study. Mult Scler. (2018) 24:963-73. doi: 10.1177/1352458517709619

44. Lechner-Scott J, Brunnschweiler H, Kappos L, Committee TSS. Is it possible to achieve cross-cultural european agreement in the assessment of neurological deficits? First experiences in the european interferonbeta 1B trial for secondary progressive MS. J Neuroimmunol. (1995) 5663:42. doi: 10.1016/0165-5728(95)98993-L

45. Cutter GR, Baier ML, Rudick RA, Cookfair DL, Fischer JS, Petkau J, et al. Development of a multiple sclerosis functional composite as a clinical trial outcome measure. Brain. (1999) 122:871-82. doi: 10.1093/brain/122.5.871

46. Ontaneda D, Fox RJ, Chataway J. Clinical trials in progressive multiple sclerosis: lessons learned and future perspectives. Lancet Neurol. (2015) 14:208-23. doi: 10.1016/S1474-4422(14)70264-9

47. Bosma LVAE, Kragt JJ, Brieva L, Khaleeli Z, Montalban X, Polman CH, et al. Progression on the multiple sclerosis functional composite in multiple sclerosis: what is the optimal cut-off for the three components? Mult Scler. (2010) 16:862-7. doi: 10.1177/1352458510370464

48. Hoogervorst ELJ, Kalkers NF, Uitdehaag BMJ, Polman CH. A study validating changes in the multiple sclerosis functional composite. Arch Neurol. (2002) 59:113-6. doi: 10.1001/archneur.59.1.113

49. Cadavid D, Cohen JA, Freedman MS, Goldman MD, Hartung H-P, Havrdova E, et al. The EDSS-Plus, an improved endpoint for disability progression in secondary progressive multiple sclerosis. Mult Scler. (2017) 23:94105. doi: $10.1177 / 1352458516638941$

50. Wolinsky JS, Montalban X, Hauser SL, Giovannoni G, Vermersch P, Bernasconi C, et al. Evaluation of no evidence of progression or active disease (NEPAD) in patients with primary progressive multiple sclerosis in the ORATORIO trial. Ann Neurol. (2018) 84:527-36. doi: 10.1002/ana.25313

51. Motl RW, Cohen JA, Benedict R, Phillips G, LaRocca N, Hudson LD, et al. Validity of the timed 25-foot walk as an ambulatory performance outcome measure for multiple sclerosis. Mult Scler. (2017) 23:70410. doi: $10.1177 / 1352458517690823$

52. Feys P, Lamers I, Francis G, Benedict R, Phillips G, LaRocca N, et al. The Nine-Hole Peg Test as a manual dexterity performance measure for multiple sclerosis. Mult Scler. (2017) 23:711-20. doi: 10.1177/1352458517690824

53. Balcer LJ, Raynowska J, Nolan R, Galetta SL, Kapoor R, Benedict R, et al. Validity of low-contrast letter acuity as a visual performance outcome measure for multiple sclerosis. Mult Scler. (2017) 23:73447. doi: $10.1177 / 1352458517690822$

54. Sola-Valls N, Blanco $\mathrm{Y}$, Sepúlveda M, Llufriu S, MartínezLapiscina EH, La Puma D, et al. Walking function in clinical monitoring of multiple sclerosis by telemedicine. J Neurol. (2015) 262:1706-13. doi: 10.1007/s00415-015-7764-x

55. Block VJ, Bove R, Zhao C, Garcha P, Graves J, Romeo AR, et al. Association of Continuous Assessment Of Step Count By Remote Monitoring With Disability Progression Among Adults With Multiple Sclerosis. JAMA Netw Open. (2019) 2:e190570. doi: 10.1001/jamanetworkopen.2019.0570

56. Dawson J, Doll H, Fitzpatrick R, Jenkinson C, Carr AJ. The routine use of patient reported outcome measures in healthcare settings. BMJ. (2010) 340:c186. doi: 10.1136/bmj.c186

57. Zhang Y, Taylor BV, Simpson S, Blizzard L, van der Mei I. Patient-reported outcomes are worse for progressive-onset multiple sclerosis than relapseonset multiple sclerosis, particularly early in the disease process. Eur J Neurol. (2019) 26:155-61. doi: 10.1111/ene.13786

58. Khurana V, Sharma H, Afroz N, Callan A, Medin J. Patient-reported outcomes in multiple sclerosis: a systematic comparison of available measures. Eur J Neurol. (2017) 24:1099-7. doi: 10.1111/ene.13339

59. Jenkinson C, Coulter A, Wright L. Short form 36 (SF36) health survey questionnaire: normative data for adults of working age. BMJ. (1993) 306:1437-440. doi: 10.1136/bmj.306.6890.1437

60. Prevolnik Rupel V, Divjak M, Zrubka Z, Rencz F, Gulácsi L, Golicki D, et al. EQ-5D studies in nervous system diseases in eight Central and East
European countries: a systematic literature review. Eur J Heal Econ. (2019) 20:109-17. doi: 10.1007/s10198-019-01068-9

61. Simeoni M, Auquier P, Fernandez O, Flachenecker P, Stecchi $\mathrm{S}$, Constantinescu $\mathrm{C}$, et al. Validation of the multiple sclerosis international quality of life questionnaire. Mult Scler. (2008) 14:219-30. doi: 10.1177/1352458507080733

62. Hobart J, Lamping D, Fitzpatrick R, Riazi A, Thompson A. The Multiple Sclerosis Impact Scale (MSIS-29): a new patient-based outcome measure. Brain. (2001) 124:962-73. doi: 10.1093/brain/124.5.962

63. Hobart JC, Riazi A, Lamping DL, Fitzpatrick R, Thompson AJ. Measuring the impact of MS on walking ability: the 12-Item MS Walking Scale (MSWS12). Neurology. (2003) 60:31-6. doi: 10.1212/WNL.60.1.31

64. Kos D, Kerckhofs E, Carrea I, Verza R, Ramos M, Jansa J. Evaluation of the modified fatigue impact scale in four different European countries. Mult Scler. (2005) 11:76-80. doi: 10.1191/1352458505ms1117oa

65. Kalb R, Beier M, Benedict RH, Charvet L, Costello K, Feinstein A, et al. Recommendations for cognitive screening and management in multiple sclerosis care. Mult Scler. (2018) 24:1665-80. doi: 10.1177/1352458518803785

66. Amato MP, Morra VB, Falautano M, Ghezzi A, Goretti B, Patti F, et al. Cognitive assessment in multiple sclerosis-an Italian consensus. Neurol Sci. (2018) 39:1317-24. doi: 10.1007/s10072-018-3427-x

67. Amato MP, Prestipino E, Bellinvia A. Identifying risk factors for cognitive issues in multiple sclerosis. Expert Rev Neurother. (2019) 19:33347. doi: 10.1080/14737175.2019.1590199

68. Dekker I, Eijlers AJC, Popescu V, Balk LJ, Vrenken H, Wattjes MP, et al. Predicting clinical progression in multiple sclerosis after 6 and 12 years. Eur J Neurol. (2019) 26:893-902. doi: 10.1111/ene.13904

69. Planche V, Gibelin M, Cregut D, Pereira B, Clavelou P. Cognitive impairment in a population-based study of patients with multiple sclerosis: differences between late relapsing-remitting, secondary progressive and primary progressive multiple sclerosis. Eur J Neurol. (2016) 23:2829. doi: 10.1111/ene.12715

70. Sumowski JF, Benedict R, Enzinger C, Filippi M, Geurts JJ, Hamalainen P, et al. Cognition in multiple sclerosis: State of the field and priorities for the future. Neurology. (2018) 90:278-88. doi: 10.1212/WNL.0000000000004977

71. Morrow SA, Drake A, Zivadinov R, Munschauer F, Weinstock-Guttman B, Benedict RHB. Predicting loss of employment over three years in multiple sclerosis: clinically meaningful cognitive decline. Clin Neuropsychol. (2010) 24:1131-45. doi: 10.1080/13854046.2010.511272

72. Moccia M, Lanzillo R, Palladino R, Chang KC-M, Costabile T, Russo C, et al. Cognitive impairment at diagnosis predicts 10-year multiple sclerosis progression. Mult Scler. (2016) 22:659-67. doi: 10.1177/13524585155 99075

73. Deloire M, Ruet A, Hamel D, Bonnet M, Brochet B. Early cognitive impairment in multiple sclerosis predicts disability outcome several years later. Mult Scler. (2010) 16:581-7. doi: 10.1177/1352458510362819

74. Christodoulou C, Melville P, Scherl WF, Macallister WS, Abensur RL, Troxell RM, et al. Negative affect predicts subsequent cognitive change in multiple sclerosis. J Int Neuropsychol Soc. (2009) 15:5361. doi: 10.1017/S135561770809005X

75. Debouverie M, Pittion-Vouyovitch S, Louis S, Guillemin F. Natural history of multiple sclerosis in a population-based cohort. Eur J Neurol. (2008) 15:916-21. doi: 10.1111/j.1468-1331.2008.02241.x

76. Pardini M, Uccelli A, Grafman J, Yaldizli Ö, Mancardi G, Roccatagliata L. Isolated cognitive relapses in multiple sclerosis. J Neurol Neurosurg Psychiatry. (2014) 85:1035-7. doi: 10.1136/jnnp-2013-307275

77. Filippi M, Preziosa P, Rocca MA. MRI in multiple sclerosis: what is changing? Curr Opin Neurol. (2018) 31:386-95. doi: 10.1097/WCO.0000000000000572

78. Petracca M, Margoni M, Bommarito G, Inglese M. Monitoring progressive multiple sclerosis with novel imaging techniques. Neurol Ther. (2018) 7:26585. doi: 10.1007/s40120-018-0103-2

79. Ciotti JR, Cross AH. Disease-modifying treatment in progressive multiple sclerosis. Curr Treat Options Neurol. (2018) 20:12. doi: 10.1007/s11940-018-0496-3

80. Tintore M, Rovira A., Rio J, Otero-Romero S, Arrambide G, Tur C, et al. Defining high, medium and low impact prognostic factors for developing multiple sclerosis. Brain. (2015) 138:1863-74. doi: 10.1093/brain/awv105 
81. Wattjes MP, Rovira À, Miller D, Yousry TA, Sormani MP, de Stefano MP, et al. MAGNIMS consensus guidelines on the use of MRI in multiple sclerosisestablishing disease prognosis and monitoring patients. Nat Rev Neurol. (2015) 11:597-606. doi: 10.1038/nrneurol.2015.157

82. Brownlee WJ, Altmann DR, Prados F, Miszkiel KA, Eshaghi A, Gandini Wheeler-Kingshott CAM, et al. Early imaging predictors of long-term outcomes in relapse-onset multiple sclerosis. Brain. (2019) 142:227687. doi: 10.1093/brain/awz156

83. Elliott C, Wolinsky JS, Hauser SL, Kappos L, Barkhof F, Bernasconi C, et al. Slowly expanding/evolving lesions as a magnetic resonance imaging marker of chronic active multiple sclerosis lesions. Mult Scler. (2019) 25:191525. doi: $10.1177 / 1352458518814117$

84. Cortese R, Collorone S, Ciccarelli O, Toosy AT. Advances in brain imaging in multiple sclerosis. Ther Adv Neurol Disord. (2019) 12:1756286419859722. doi: 10.1177/1756286419859722

85. Kaunzner UW, Gauthier SA. MRI in the assessment and monitoring of multiple sclerosis: an update on best practice. Ther Adv Neurol Disord. (2017) 10:247-61. doi: 10.1177/1756285617708911

86. Absinta M, Sati P, Masuzzo F, Nair G, Sethi V, Kolb H, et al. Association of chronic active multiple sclerosis lesions with disability in vivo. JAMA Neurol. (2019) 76:1474-83. doi: 10.1001/jamaneurol.2019.2399

87. Calabrese M, Rocca MA, Atzori M, Mattisi I, Favaretto A, Perini P, et al. A 3 -year magnetic resonance imaging study of cortical lesions in relapse-onset multiple sclerosis. Ann Neurol. (2010) 67:376-83. doi: 10.1002/ana.21906

88. Calabrese M, Poretto V, Favaretto A, Alessio S, Bernardi V, Romualdi C, et al. Cortical lesion load associates with progression of disability in multiple sclerosis. Brain. (2012) 135:2952-61. doi: 10.1093/brain/aws246

89. Kearney H, Miszkiel KA, Yiannakas MC, Altmann DR, Ciccarelli O, Miller DH. Grey matter involvement by focal cervical spinal cord lesions is associated with progressive multiple sclerosis. Mult Scler. (2016) 22:91020. doi: $10.1177 / 1352458515604905$

90. Jonas SN, Izbudak I, Frazier AA, Harrison DM. Longitudinal persistence of meningeal enhancement on postcontrast 7T 3DFLAIR MRI in multiple sclerosis. AJNR Am J Neuroradiol. (2018) 39:1799-805. doi: 10.3174/ajnr.A5796

91. Dupuy SL, Tauhid S, Kim G, Chu R, Tummala S, Hurwitz S, et al. MRI detection of hypointense brain lesions in patients with multiple sclerosis: T1 spin-echo vs. gradient-echo. Eur J Radiol. (2015) 84:156468. doi: 10.1016/j.ejrad.2015.05.004

92. Steenwijk MD, Geurts JJG, Daams M, Tijms BM, Wink AM, Balk LJ, et al. Cortical atrophy patterns in multiple sclerosis are non-random and clinically relevant. Brain. (2015) 139:115-26. doi: 10.1093/brain/awv337

93. Sastre-Garriga J, Pareto D, Rovira À. Brain atrophy in multiple sclerosis: clinical relevance and technical aspects. Neuroimaging Clin N Am. (2017) 27:289-300. doi: 10.1016/j.nic.2017.01.002

94. Casserly C, Seyman EE, Alcaide-Leon P, Guenette M, Lyons C, Sankar S, et al. Spinal cord atrophy in multiple sclerosis: a systematic review and meta-analysis. J Neuroimaging. (2018) 28:556-86. doi: 10.1111/jon.12553

95. Lukas C, Knol DL, Sombekke MH, Bellenberg B, Hahn HK, Popescu V, et al. Cervical spinal cord volume loss is related to clinical disability progression in multiple sclerosis. J Neurol Neurosurg Psychiatry. (2015) 86:410-18. doi: 10.1136/jnnp-2014-308021

96. Rocca MA, Absinta M, Filippi M. The role of advanced magnetic resonance imaging techniques in primary progressive MS. J Neurol. (2012) 259:61121. doi: $10.1007 / \mathrm{s} 00415-011-6195-6$

97. Fernandez O, Martin R, Rovira A, Llufriu S, Vidal-Jordana A, FernandezSanchez VE, et al. Biomarkers in multiple sclerosis: an update for 2014. Rev Neurol. (2014) 58:553-70. doi: 10.33588/rn.5812.2014247

98. Narayana PA. Magnetic resonance spectroscopy in the monitoring of multiple sclerosis. J Neuroimaging. (2005) 15:46S. doi: $10.1177 / 1051228405284200$

99. Fujiwara E, Kmech JA, Cobzas D, Sun H, Seres P, Blevins G, et al. Cognitive implications of deep gray matter iron in multiple sclerosis. AJNR Am J Neuroradiol. (2017) 38:942-8. doi: 10.3174/ajnr.A5109

100. Langkammer C, Liu T, Khalil M, Enzinger C, Jehna M, Fuchs S, et al. Quantitative susceptibility mapping in multiple sclerosis. Radiology. (2013) 267:551-9. doi: 10.1148/radiol.12120707
101. Aminoff MJ. Electrophysiologic evaluation of patients with multiple sclerosis. Neurol Clin. (1985) 3:663-74. doi: 10.1016/S0733-8619(18) 31028-4

102. Ferrazzano G, Crisafulli SG, Baione V, Tartaglia M, Cortese A, Frontoni $\mathrm{M}$, et al. Early diagnosis of secondary progressive multiple sclerosis: focus on fluid and neurophysiological biomarkers. J Neurol. (2020) doi: 10.1007/s00415-020-09964-4

103. Comabella M, Montalban X. Body fluid biomarkers in multiple sclerosis. Lancet Neurol. (2014) 13:113-26. doi: 10.1016/S1474-4422(13)70233-3

104. Gasperi C, Salmen A, Antony G, Bayas A, Heesen C, Kümpfel T, et al. Association of intrathecal immunoglobulin $\mathrm{g}$ synthesis with disability worsening in multiple sclerosis. JAMA Neurol. (2019) 76:8419. doi: 10.1001/jamaneurol.2019.0905

105. Khademi M, Kockum I, Andersson ML, Iacobaeus E, Brundin L, Sellebjerg F, et al. Cerebrospinal fluid CXCL13 in multiple sclerosis: a suggestive prognostic marker for the disease course. Mult Scler. (2011) 17:33543. doi: $10.1177 / 1352458510389102$

106. Petzold A, Eikelenboom MJ, Gveric D, Keir G, Chapman M, Lazeron RHC, et al. Markers for different glial cell responses in multiple sclerosis: clinical and pathological correlations. Brain. (2002) 125:146273. doi: 10.1093/brain/awf165

107. Axelsson M, Malmeström C, Nilsson S, Haghighi S, Rosengren L, Lycke J. Glial fibrillary acidic protein: a potential biomarker for progression in multiple sclerosis. J Neurol. (2011) 258:8828. doi: 10.1007/s00415-010-5863-2

108. Martínez MAM, Olsson B, Bau L, Matas E, Cobo Calvo Á, Andreasson $\mathrm{U}$, et al. Glial and neuronal markers in cerebrospinal fluid predict progression in multiple sclerosis. Mult Scler. (2015) 21:550-61. doi: 10.1177/1352458514549397

109. Salzer J, Svenningsson A, Sundström P. Neurofilament light as a prognostic marker in multiple sclerosis. Mult Scler. (2010) 16:28792. doi: $10.1177 / 1352458509359725$

110. Cantó E, Barro C, Zhao C, Caillier SJ, Michalak Z, Bove R, et al. Association between serum neurofilament light chain levels and long-term disease course among patients with multiple sclerosis followed up for 12 years. JAMA Neurol. (2019) 76:1359-66. doi: 10.1001/jamaneurol.2019.2137

111. Pérez-Miralles F, Prefasi D, García-Merino A, Gascón-Giménez F, Medrano $\mathrm{N}$, Castillo-Villalba J, et al. CSF chitinase 3-like-1 association with disability of primary progressive MS. Neurol Neuroimmunol Neuroinflamm. (2020) 7:e815. doi: 10.1212/NXI.0000000000000815

112. Barro C, Benkert P, Disanto G, Tsagkas C, Amann M, Naegelin Y, et al. Serum neurofilament as a predictor of disease worsening and brain and spinal cord atrophy in multiple sclerosis. Brain. (2018) 141:238291. doi: 10.1093/brain/awy154

113. Disanto G, Barro C, Benkert P, Naegelin Y, Schädelin S, Giardiello A, et al. Serum Neurofilament light: a biomarker of neuronal damage in multiple sclerosis. Ann Neurol. (2017) 81:857-70. doi: 10.1002/ana.24954

114. Martin S-J, McGlasson S, Hunt D, Overell J. Cerebrospinal fluid neurofilament light chain in multiple sclerosis and its subtypes: a metaanalysis of case-control studies. J Neurol Neurosurg Psychiatry. (2019) 90:1059-67. doi: 10.1136/jnnp-2018-319190

115. Petzold A, de Boer JF, Schippling S, Vermersch P, Kardon R, Green A, et al. Optical coherence tomography in multiple sclerosis: a systematic review and meta-analysis. Lancet Neurol. (2010) 9:921-32. doi: 10.1016/S1474-4422(10)70168-X

116. Petzold A, Balcer LJ, Calabresi PA, Costello F, Frohman TC, Frohman $\mathrm{EM}$, et al. Retinal layer segmentation in multiple sclerosis: a systematic review and meta-analysis. Lancet Neurol. (2017) 16:797-812. doi: 10.1016/S1474-4422(17)30278-8

117. Martinez-Lapiscina EH, Arnow S, Wilson JA, Saidha S, Preiningerova $\mathrm{JL}$, Oberwahrenbrock $\mathrm{T}$, et al. Retinal thickness measured with optical coherence tomography and risk of disability worsening in multiple sclerosis: a cohort study. Lancet Neurol. (2016) 15:574-84. doi: 10.1016/S1474-4422(16)00068-5

118. Bsteh G, Hegen H, Teuchner B, Amprosi M, Berek K, Ladstätter F, et al. Peripapillary retinal nerve fibre layer as measured by optical coherence tomography is a prognostic biomarker not only for physical but also for 
cognitive disability progression in multiple sclerosis. Mult Scler. (2019) 25:196-203. doi: 10.1177/1352458517740216

119. Baldassari LE, Fox RJ. Therapeutic advances and challenges in the treatment of progressive multiple sclerosis. Drugs. (2018) 78:154966. doi: 10.1007/s40265-018-0984-5

120. Correale J, Gaitán MI, Ysrraelit MC, Fiol MP. Progressive multiple sclerosis: from pathogenic mechanisms to treatment. Brain. (2017) 140:52746. doi: 10.1093/brain/aww258

121. Lassmann H. Targets of therapy in progressive MS. Mult Scler. (2017) 23:1593-9. doi: 10.1177/1352458517729455

122. Kappos L, Bar-Or A, Cree BAC, Fox RJ, Giovannoni G, Gold R, et al. Siponimod versus placebo in secondary progressive multiple sclerosis (EXPAND): a double-blind, randomised, phase 3 study. Lancet. (2018) 391:1263-73.

123. Castillo-Trivino T, Braithwaite D, Bacchetti P, Waubant E. Rituximab in relapsing and progressive forms of multiple sclerosis: a systematic review. PLoS One. (2013) 8:e66308. doi: 10.1371/journal.pone.0066308

124. Hawker K, O’Connor P, Freedman MS, Calabresi PA, Antel J, Simon J, et al. Rituximab in patients with primary progressive multiple sclerosis: results of a randomized double-blind placebo-controlled multicenter trial. Ann Neurol. (2009) 66:460-71. doi: 10.1002/ana.21867

125. European Medicines Agency Website. EPAR IFN beta $1 b$ sc. Available online at: https://www.ema.europa.eu/en/documents/productinformation/extavia-epar-product-information_en.pdf (accessed June 17, 2020).

126. European Medicines Agency Website. EPAR IFN beta 1a sc. Available online at: https:/www.ema.europa.eu/en/documents/productinformation/rebif-epar-product-information_en.pdf (accessed June 17, 2020).

127. European Medicines Agency Website. EPAR Mitoxantrone. Available online at: https://www.ema.europa.eu/en/documents/referral/novantronearticle-30-referral-annex-iii_en.pdf (accessed June 17, 2020).

128. European Medicines Agency Website. EPAR Ocrelizumab. Available online at: https://www.ema.europa.eu/en/documents/product-information/ ocrevus-epar-product-information_en.pdf (accessed June 17, 2020).

129. European Medicines Agency Website. EPAR Siponimod. Available online at: https://www.ema.europa.eu/en/medicines/human/EPAR/mayzent (Accessed June 17, 2020).

130. La Mantia L, Vacchi L, Rovaris M, Di Pietrantonj C, Ebers G, Fredrikson $S$, et al. Interferon $\beta$ for secondary progressive multiple sclerosis: a systematic review. J Neurol Neurosurg Psychiatry. (2013) 84:42026. doi: 10.1136/jnnp-2012-303291

131. Leary SM, Miller DH, Stevenson VL, Brex PA, Chard DT, Thompson AJ. Interferon $\beta$-1a in primary progressive MS: an exploratory, randomized, controlled trial. Neurology. (2003) 60:44-51. doi: 10.1212/WNL.60.1.44

132. Montalban X, Sastre-Garriga J, Tintoré M, Brieva L, Aymerich FX, Río J, et al. A single-center, randomized, double-blind, placebo-controlled study of interferon beta-1b on primary progressive and transitional multiple sclerosis. Mult Scler. (2009) 15:1195-205. doi: 10.1177/1352458509 106937

133. Ziemssen T, Rauer S, Stadelmann C, Henze T, Koehler J, Penner IK, et al. Evaluation of study and patient characteristics of clinical studies in primary progressive multiple sclerosis: A systematic review. PLOS ONE. (2015) 10:e138243. doi: 10.1371/journal.pone.0138243

134. Lublin F, Miller DH, Freedman MS, Cree BAC, Wolinsky JS, Weiner H, et al. Oral fingolimod in primary progressive multiple sclerosis (INFORMS): a phase 3, randomised, double-blind, placebo-controlled trial. Lancet. (2016) 387:1075-84. doi: 10.1016/S0140-6736(15)01314-8

135. Tur C, Montalban X. Progressive MS trials: lessons learned. Mult Scler. (2017) 23:1583-92. doi: 10.1177/1352458517729460

136. Kapoor R, Ho PR, Campbell N, Chang I, Deykin A, Forrestal F, et al. Effect of natalizumab on disease progression in secondary progressive multiple sclerosis (ASCEND): a phase 3, randomised, double-blind, placebocontrolled trial with an open-label extension. Lancet Neurol. (2018) 17:40515. doi: 10.1016/S1474-4422(18)30069-3

137. Montalban X, Hauser SL, Kappos L, Arnold DL, Bar-Or A, Comi G, et al. Ocrelizumab versus placebo in primary progressive multiple sclerosis. $N$ Engl J Med. (2017) 376:209-20. doi: 10.1056/NEJMoa1606468

138. Wolinsky JS, Arnold DL, Brochet B, Hartung HP, Montalban X, Naismith RT, et al. Long-term follow-up from the ORATORIO trial of ocrelizumab for primary progressive multiple sclerosis: a post-hoc analysis from the ongoing open-label extension of the randomised, placebo-controlled, phase 3 trial. Lancet Neurol. (2020) 19:998-1009. doi: 10.1016/S1474-4422(20)30342-2

139. Rae-Grant A, Day GS, Marrie RA, Rabinstein A, Cree BAC, et al. Practice guideline recommendations summary: disease-modifying therapies for adults with multiple sclerosis: report of the guideline development, dissemination, and implementation subcommittee of the american academy of neurology. Neurology. (2018) 90:777-88. doi: 10.1212/WNL.0000000000005347

Conflict of Interest: VM-L has received compensation for consulting services and speaking honoraria from Almirall, Biogen, Genzyme, Merck Serono, Novartis, Roche, Terumo, Sanofi and Teva. LB-R has received compensation for consulting services and speaking honoraria from Biogen, Sanofy-Genzyme, Merck Serono, Novartis, Roche, and Teva. JC-P has received compensation for consulting services from Roche. SE-M has received compensation for consulting services and speaking honoraria from Biogen Idec, Novartis, Merck, Bayer, Sanofi-Genzyme, Roche, and Teva. JF-L has received compensation for consulting services from Roche. LF has received compensation for consulting services from Roche, Merck, Novartis and Genzyme, for speaking honoraria from Roche, Merck and Novartis, and for traveling grants from Genzyme, Roche and Novartis. YH has received compensation for consulting services from Roche and Merck, Novartis, Teva and Genzyme, for speaking, honoraria from Roche, Merck and Novartis, and for traveling grants from Merck, Genzyme, Roche and Novartis. NT has received compensation for consulting services, traveling grants and speaking honoraria from Bayer Schering Pharma, Biogen Idec, Merck Serono, Novartis, SanofiAventis, Teva, and Roche. AV-J has received investigation grants Juan Rodes (JR16/00024) from Fondo de Investigaciones Sanitarias, Instituto de Salud Carlos III, and has received compensation for consulting services, participation in advisory boards, and speaking honoraria from Novartis, Stendhal, Roche, Teva, Biogen, and Genzyme-Sanofi. FP-M has received compensation for consulting services and speaking honoraria from Roche, Sanofi-Genzyme y Biogen, and speaking honoraria from Novartis, Almirall and Teva.

Copyright (C) 2021 Meca-Lallana, Berenguer-Ruiz, Carreres-Polo, Eichau-Madueño, Ferrer-Lozano, Forero, Higueras, Téllez Lara, Vidal-Jordana and Pérez-Miralles. This is an open-access article distributed under the terms of the Creative Commons Attribution License (CC BY). The use, distribution or reproduction in other forums is permitted, provided the original author(s) and the copyright owner(s) are credited and that the original publication in this journal is cited, in accordance with accepted academic practice. No use, distribution or reproduction is permitted which does not comply with these terms. 